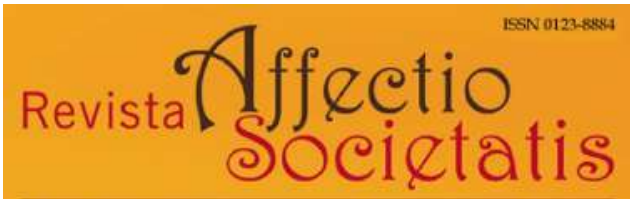

Departamento de Psicoanálisis I Universidad de Antioquia

Revista Affectio Societatis

Departamento de Psicoanálisis

Universidad de Antioquia

revistaaffectiosocietatis@udea.edu.co

ISSN (versión electrónica): 0123-8884

Colombia

2020

Marcelo Ricardo Pereira

¿Qué quiere un adolescente? Los límites del psicoanálisis y los múltiples modos de interpretar a ese sujeto

Revista Affectio Societatis, Vol. 17, N. ${ }^{0} 32$, enero-junio de 2020 Art. \# 6 (pp. 129-159)

Departamento de Psicoanálisis, Universidad de Antioquia Medellín, Colombia 


\title{
¿QUÉ QUIERE UN ADOLESCENTE? LOS LÍMITES DEL PSICOANÁLISIS Y LOS MÚLTIPLES MODOS DE INTERPRETAR A ESE SUJETO
}

\author{
Marcelo Ricardo Pereira1 \\ Universidad Federal de Minas Gerais, Brasil \\ mrp@fae.ufmg.br \\ ORCID: 0000 -0002-0977-9124 \\ DOI: 10.17533/udea.affs.v17n32a06
}

\section{Resumen}

Con el objetivo de dilatar teóricamente algunas de las perspectivas de análisis y descripciones sobre quiénes son los adolescentes a que dirigimos la escucha ofreciendo la palabra y la experiencia psicoanalítica en el ámbito del trabajo social, el presente artículo interroga los límites de las interpretaciones culturalista y estructuralista en psicoanálisis para presentar las múltiples maneras de concebir a esos sujetos que se ven desde el modo de Telé- maco, esperando que algo del padre retorne, hasta adolescentes que se renombran y usan tales acciones para vincularse entre sí confrontando el mundo adulto. Con estos últimos se trata la nominación, tema de investigación que nos ayuda a responder la cuestión: ¿qué quiere al final un adolescente?

Palabras Clave Adolescencia; Psicoanálisis; Modos múltiplos de síntoma; Nominación; Re-bautizo

1 Psicólogo, psicoanalista, doctor en Educación y post-doctor en Teoría Psicoanalítica (UFRJ, Brasil) y Educación Social (UOC, España). Es profesor de "Psicología, psicoanálisis y educación" del Programa de Postgrado y de la Facultad de Educación de la Universidad Federal de Minas Gerais (UFMG, Brasil). Realizó pasantía docente en Psicología Educativa (UNR, Argentina) y en Psicología, Educación y Desarrollo Humano (UdelaR, Uruguay). Instituyó el laboratorio LPPE (UON, Angola), es "investigador productividad" del CNPq y de la Fapemig y publicó 11 libros autorales y compilados sobre sus temas de investigación. 


\section{WHAT DOES AN ADOLESCENT WANT? THE LIMITS OF PSYCHOANALYSIS AND THE MULTIPLE WAYS OF INTERPRETING THAT SUBJECT}

\section{Abstract}

To theoretically dilate some of the perspectives of analysis and descriptions about who are the adolescents to whom we direct the listening by offering the word and the psychoanalytic experience in the field of social work, this paper questions the limits of the culturalist and structuralist interpretations in psychoanalysis to present the multiple ways of conceiving these subjects who are seen from the mode of Telemachus, waiting for something of the father to return, to adolescents who rename themselves and use such actions to link themselves by confronting the adult world. Naming is addressed from the latter, a research topic that helps us to answer this question: What does an adolescent want in the end?

Keywords: Adolescence; Psychoanalysis; Multiple symptom modes; Naming; Re-baptism

\section{QUE VEUT L'ADOLESCENT ? LES LIMITES DE LA PSYCHANALYSE ET LES MODES MULTIPLES D'INTERPRÉTER CE SUJET}

\section{Résumé}

Dans le but d'élargir théoriquement quelques perspectives d'analyse et descriptions des adolescents que l'on écoute et à qui on laisse la parole et la possibilité d'expérience psychanalytique dans le domaine du travail social, cet article interroge les limites des interprétations culturaliste et structuraliste en psychanalyse. De multiples manières de concevoir ces sujets sont donc présentées qui, à l'image de Télémaque, attendent que quelque chose du père revienne, ou bien ils se renomment et se servent de ces actions pour établir des liens entre eux-mêmes en les confrontant au monde des adultes. Le sujet de la nomination est abordé avec ce type d'adolescents, sujet qui aide à répondre à la question : finalement, que veut l'adolescent?

Mots-clés : adolescence ; psychanalyse ; modes multiples du symptôme ; nomination ; re-baptême

Recibido: 29/08/2019 • Aprobado: 8/10/2019 
¿Quiénes son los adolescentes a que dirigimos la escucha ofreciendo la palabra y la experiencia psicoanalítica en el ámbito del trabajo social? ¿Cómo hacer hablar a esos sujetos estigmatizados o muchas veces prevenidos y acallados institucionalmente en el sentido de poder conducir algo de sus deseos a inscribirse más allá de la norma, pero no sin ella?

Esas preguntas provienen de nuestros cuestionamientos y lucha contra la moral segregadora de una sociedad no dispuesta a incluir su masa de nuevos esclavos (Souza, 2017). Las marcas en el cuerpo y en el territorio, la toxicomanía, la híper erotización desinhibida, el escarnio a la autoridad, las provocaciones del lenguaje, las seducciones incontinentes, la pregnancia a los medios sensacionalistas, la adhesión incondicional a la delincuencia por parte de nuestros adolescentes pueden ser considerados muy probablemente como resistencias, incluso sintomáticas, frente a esa moral segregadora de una sociedad adulta que les niega reconocimiento (Gurski y Pereira, 2016).

Hay que escuchar a los jóvenes para saber, incluso, si es realmente sintomático de varios de ellos lidiar con lo real, esto es, con el agujero no cubierto por lo simbólico, resultante de un sujeto no ser o de no sentirse algo para el otro o para la polis. Se trata de un agujero irreductible que aquí, en nuestras ciudades latinoamericanas, gana contornos aún peores en razón que ni el Estado, ni las condiciones sociales y tampoco algún proyecto de nación, contra su origen colonial y esclavista, surge para mínimamente cubrirlo.

Pero ¿será que esas respuestas o síntomas, que muchas veces se presentan de manera irreflexiva, vana y difusa, no dejan de ser también un manejo (en ciertos casos hasta inventivo) de los jóvenes para insistir en inscribirse y, forzadamente, renombrarse (Bolaños, 2017) en un mundo que no se intimida en in-visibilizarlos? Se vuelve necesario que sepamos crear lugares para acoger esos jóvenes y ayudarlos a traducir en palabras y en actos lo que ellos sólo consiguen decir a través de la irreflexión del síntoma, de la transgresión o de aquello que los lleva a lo peor (Pereira, 2019).

¿Quiénes son ellos al final? ¿Quiénes son los adolescentes de nuestros tiempos que, con efecto, deben ser acogidos y escuchados 
dada su condición social adversa? ¿Cuáles son las maneras del psicoanálisis interpretarlos o teorizarlos más allá de los presupuestos desarrollistas y del biologismo?

Pasemos a hablar sobre ese sujeto que quizás situamos en un entre lugares o un lugar entre dos, sin necesariamente pertenecer a ninguno, pero con exigencia de un "trabajo social a prueba de la clínica psicoanalítica" (Ponnou, 2016) que, por medio del habla y la escucha, quiere inscribirlo en un mundo cada vez más juvenilizado. Proponemos un gran desvío acerca de cómo el psicoanálisis interpreta hoy la adolescencia, incluso sus límites, para luego mostrar otras tantas maneras de interpretarla, terminando en la que Bolaños (2017) presenta como rebautizo de los sujetos.

\section{Dos formas como el psicoanálisis interpreta la adolescencia y lo que eso dice respecto al adolescente antisocial ${ }^{2}$}

En razón de situaciones propias de ese momento de pasaje que las sociedades occidentales produjeron, sobre todo a lo largo del siglo xx hasta los días de hoy, nuestros adolescentes tienden a presentar dificultades para encontrar un lugar de representación y nominación en el espacio social. Es así que muchas veces la violencia y los actos antisociales de los jóvenes pueden funcionar como una forma de expresión del malestar que los asalta (Gurski, 2012).

Ese "malestar" -una forma de angustia, como lo dice Freud (2010/1930)-, puede llevar a muchos adolescentes a desorganizarse en continuos ensayos de recubrimiento de su psiquismo perforado por lo real en busca de solucionar los dilemas a los que se ven enfrentados. Sin recursos civilizatorios suficientes que supuestamente les permitan crear resoluciones menos dañinas a su propio ser, notamos, con efecto, que la inmensa mayoría de los adolescentes inventa salidas sintomáticas para lidiar con efectos de vacío que esos ensayos no

2 "Antisocial": adjetivo que adoptamos con base en Winnicott (2005). 
consiguen cubrir. Ellos tienden a hacer de su propia adolescencia un síntoma social de la cultura contemporánea o una especie de nebulosa con contornos opacos y mal definidos. Si no, veamos.

Para efectos jurídicos, a grueso modo, la adolescencia en Brasil y en la mayoría de los países latinoamericanos es definida para individuos en desarrollo que se encuentran precisamente entre 12 y 18 años incompletos, siendo la familia y, en ausencia de ella, el Estado, los responsables tutelares por su educación, salud, ocio, abrigo e interacción social. Desde el punto de vista de la sociología, la noción de adolescencia es poco o nada considerada en favor de la noción de juventud con contornos de edad menos precisos, pero que describe política, económica y socialmente el modo de existencia de sujetos que se encuentran entre mediados de su segunda década de vida y final de su tercera.

A su vez, desde el punto de vista psicológico -y también psicoanalítico-, eso se complejiza: al centrar sus esfuerzos de análisis en la singularidad subjetiva, se notará que cada sujeto se constituye de manera única en la historia y en el medio social en el que se encuentra. La adolescencia o la juventud de un sujeto va a contar, seguramente, con temporalidades y vivencias diferentes de la adolescencia o juventud del otro, aunque ambos se encuentren en un mismo ambiente social. De modo que no hay como universalizar conductas y actos de ese momento de la vida sin que se incurra en una imprecisión descriptiva del análisis de cada sujeto. Aun así, algún consenso puede ser admitido en lo que se refiere al prisma psíquico, sobre esa nebulosa temporal que se volvió la adolescencia de nuestro medio: su comienzo se dará alrededor de la manifestación corporal de la pubertad, pudiendo ser antes o después de ella, hasta el momento en que el sujeto pasa a responsabilizarse por sus propios actos del punto de vista económico, jurídico, social y sexual. O sea, la adolescencia se daría como el decline de la infancia hasta el ascenso de su condición de adulto joven.

Estar en ese momento de transición adolescente en nuestras sociedades no es nada fácil, ya que es estar entre dos lugares y no pertenecer propiamente a ninguno. Ni a la infancia, muchas veces idealizada, contada y protegida, aunque no raramente amenazada o maltratada, 
ni a la adultez que le garantizaría alguna autonomía para responder y responsabilizarse por sus propios actos, sean ellos económicos, jurídicos, sociales, sexuales, como ya se describieron, o, dicho a nuestra forma, responsabilizarse por los propios síntomas. La adolescencia parece entonces ser la resultante de lugares polarizados, ambiguos y opacos, "como la perforación de un túnel desde sus dos extremos" (Freud, 1980a/1905, p.189).

El inventor del psicoanálisis reconoce la "pubertad" -término con el cual trata la adolescencia en el inicio de sus trabajos- como un momento delicado por ser una especie de efecto Nachträglichkeit (a posteriori) de la sexualidad infantil. Ella es su retorno y también su desenlace rumbo a la sexualidad adulta, como cabe deducir de Freud (1980a/1905). El joven se ve delante de algunos destinos inevitables e íntimamente ligados entre sí:

1. El desligamiento o desidentificación respecto a los padres u objetos primordiales de amor;

2. El descenso del autoerotismo o de las formas narcisistas de investimento en tales objetos;

3. La afirmación de sus ideales societarios como grupos, compañeros, formación, profesión, cónyuge, entre otros;

4. La inscripción social de su propia sexualidad, confrontándose con la diferencia entre los sexos y con la angustia de la castración, al contradecir la condición polimorfa perversa de su infancia.

No es de extrañarse que, frente a esos destinos, el adolescente de hoy busque resoluciones que desemboquen muy frecuentemente en ambivalencias, conflictos, re-bautizos y corto circuitos mal sucedidos de recubrimiento de su túnel precariamente agujereado.

Como lo plantean Boaventura Jr. y Pereira (2015), la adolescencia podría ser comprendida como un momento reciente de constitución humana occidental, caracterizada por transformaciones que suscitan y constituyen deseos de acceso a una vida adulta con un cuerpo genitalizado por una pulsión de objeto hasta entonces no experimentada. Al mismo tiempo, tales transformaciones son frenadas por el rechazo de dejar las pulsiones narcisistas que la gran mayoría de los jóvenes 
viven en la infancia. El sujeto, bajo tal condición, experimentaría una agresividad pulsional, así como cambios corporales, biológicos y, por supuesto, sociales y políticos que le exigen un trabajo psíquico igualmente agresivo, ya que el propio sujeto es, en sí, efecto de una transformación que, bajo ninguna hipótesis, podría controlar.

Y no se trataría de evolucionismo. No se puede buscar en la infancia la elaboración de estructuras que serán revividas y superadas en la adolescencia. Esa superación no significa la substitución de una vieja estructura, que desaparece, por otra nueva que concretaría una etapa de "madurez adulta". Esa superación designaría, sí, la transformación en algo nuevo desde el punto de vista lógico que conservaría de sí algo antiguo. Para la teoría psicoanalítica, dice Turbet (1999), la infancia no desaparece nunca, así como jamás se logra una madurez sexual absoluta, opuesta a la sexualidad infantil. Las organizaciones sexuales del niño están contenidas en el adulto, así como en el adolescente. Sus elementos persisten, aunque "revalorizados o resignificados en una nueva estructura" (p. 13).

En la realidad, al genitalizar su pulsión y elegir un objeto sexual fuera de su cuerpo, el adolescente necesita hacer un arduo trabajo psíquico de des-investimento de sus primeros objetos narcisistas de amor -que en nuestras sociedades son frecuentemente los padres, en especial la madre o quien la sustituye-. Tal genitalidad es fomentada por los paradigmas culturales de nuestro medio en el cual son integrados conceptos morales que excluyen de la elección de objeto a las personas intensamente revestidas en la infancia. La adolescencia sería, entonces, un operador lógico, un intento moebiano del trabajo psíquico para que el sujeto pueda llevar a cabo el encuentro con el sexo del otro y no apenas con el otro sexo, como acreditan algunos psicoanalistas, por ejemplo, Stevens (2004) y Lima (2014); sería un momento de revisitar las fantasías incestuosas al mismo tiempo que se renuncia -en parte- a los saturados narcisistas.

Aquí, más allá de las teorías de evolucionismo, que no necesariamente seguimos, se divisarían otras dos formas de interpretar psicoanalíticamente a la adolescencia. Son formas que no se excluyen mutuamente, siendo una de orientación culturalista y la otra de orientación 
estructuralista. Ambas, debemos destacar, se suman y contribuyen para las inferencias que ahora hacemos, quizás una orientación decantada de las dos con el objetivo de reflexionar sobre las múltiples formas de interpretar esa que es, en palabras de Lacadée (2011), la más delicada de las transiciones.

1). La orientación culturalista problematiza la adolescencia como fenómeno histórico reciente -un poco más de un siglo-, con base en las condiciones culturales en las que ella es producida. Una cultura cada vez más compleja pasa a exigir un tiempo mayor de formación de sus individuos para vivir en ella. Luego, si en las sociedades pre-modernas un niño era directamente catapultado a la vida adulta en razón de ritos de pasaje con expresiva eficacia simbólica, en nuestra modernidad, dado su carácter más complejo, esa eficacia se esfuma. Una de las fuertes características de la modernidad, sobre todo de la modernidad tardía, dice Ruffino (2000), es la ausencia de tradiciones y rituales de pasaje que posibiliten al sujeto adolescente significar subjetivamente ese pasaje traumático que es la transición del universo infantil hacia el adulto. Así, desprotegidos de una eficacia simbólica antes presente y practicada en las sociedades premodernas, "se volvió necesario al joven adolescer" (p. 37).

Boaventura Jr. y Pereira (2015) recuerdan que ese estatus adjudicado a los ritos de pasaje proporcionaba un contexto que, en las sociedades tradicionales, preparaba al niño para participar del sistema social, comunitario y civilizado en el que vivía. Ya en las sociedades actuales, el surgimiento de la adolescencia se vuelve un elemento de la estructura fundamental del hombre y de la mujer para que se puedan constituir como subjetividad contemporánea. Así, la adolescencia inserta en los parámetros civilizados de hoy sería la transición delicada y gradual de la instancia del púber a la condición de adulto joven, facilitada por prácticas sociales encontradas en los discursos de las sociedades de nuestro tiempo.

La adolescencia es una institución históricamente determinada, un fenómeno de la modernidad que alcanza al joven de Occidente por ocasión de la eclosión de la pubertad, cuando, por falta de dispositivos generales presentes en las organizaciones sociales premoder- 
nas o no occidentales, el pasaje del niño a joven adulto se volvió problemático. La adolescencia, lejos de ser puramente biológica o social, es antes el producto del impacto puberal y la intensificación de exigencias sociales sobre el joven en vía de dejar la infancia, bajo ciertas condiciones de cultura, que caracterizan la civilización occidental hoy y a partir del establecimiento de ciertas alteraciones en la historia de esa civilización que especifican la modernidad. (Ruffino, 2000, p. 30, traducción nuestra).

En defensa de su idea de conflicto de generaciones, propio de los tiempos modernos, Paladino (2005) trabaja con la hipótesis que esos tiempos reflejan las características de una civilización de efectos universalizantes y cosmopolitas, de cara a los vínculos comunitarios que unían cada grupo social a sus orígenes históricos y culturales. Así, la adolescencia sería el proceso que surge en consecuencia de la desaparición de la vida social y de prácticas comunitarias como, por ejemplo, los ritos tradicionales de las sociedades pre-modernas. Para la autora, la duración de la adolescencia estará directamente ligada al curso temporal necesario para que, en el ámbito subjetivo, sea posible realizar eso qué supuestamente el ritual tradicional, de forma ligera y eficaz, llevaba a cabo en los tiempos precedentes a la modernidad.

Las tradicionales ceremonias y ritos de pasaje facilitaban la conversión de la real y concreta modificación biológica y corporal presente en la pubertad, en significante constituyente para el sujeto pasar a la condición de adulto. El lapso en lo social de esos ritos crea un vacío y, consecuentemente, produce en el joven "sensaciones de extrañeza frente a este evento no simbolizado" (Ruffino, 2000, p. 50). La adolescencia se vuelve, con base en esa orientación culturalista, la resultante de ese requerimiento cultural y social aún no simbolizado.

Si fuera así, sería posible hacer conjeturas, desde el punto de vista culturalista que, hoy, ciertos actos antisociales practicados por los adolescentes pueden bien derivar, cada uno a su modo, de la necesidad de esos mismos sujetos adolescentes de encajar en sí, algún residuo suplente de ritos de pasaje. Esa suplencia les permitiría mínimamente recubrir el vacío provocado por la ausencia de una eficacia simbólica capaz de servirles como referencia social que les permitiese ubicarse como compañeros activos en el contexto de sus vínculos 
sociales. Serían solicitudes simbólicas de muerte en la búsqueda de límites o diques como intentos deformados y dolorosos de ubicarse en el mundo, de ritualizar el pasaje a la vida adulta, de remarcar el momento en que el acto lleva ventaja sobre la dimensión del sentido. Como defiende Lacadée (2011), esas serían conductas de riesgo que permitirían asegurar el valor de la existencia, apartar el miedo de la inconsistencia y de la insignificancia. Serían, antes, tentativas de existir, más que de morir o de hacer morir.

La exposición al riesgo, a la posibilidad no anónima de lastimarse o morir, de herir a otro o exterminarlo, de tomar para sí algo de él, de comprometer su futuro personal o de ponerse en peligro no deja de alterar substancialmente las posibilidades de vinculación social. Utilizando el acto social como suplencia de ritos de pasaje, justamente en defensa de hacerse parte del lazo con el otro, el desenlace resulta lo contrario de lo que él previó: la desinserción social. El adolescente, bajo esa circunstancia, se ve estigmatizado y segregado precisamente por intentar integrarse, por intentar pertenecer y hacer que los dos agujeros de su túnel se encuentren. Pero no. La segregación genera más segregación. Y muchos no dudan en adoptar la delincuencia y la rebeldía como modo sintomático que es testimonio de su falta de ser, su sufrimiento, su escarnio, su necesidad interior de enfrentar al mundo para deshacerse de su malestar, o sea, deshacerse de la angustia de vivir, en razón del vacío simbólico de su existencia. Imponerse límites a sí mismos con conductas de riesgo, algo delicado y de difícil manejo, les puede servir de sedantes para la angustia, de anestesia de la existencia o de algún pedido de ayuda. Se vuelve imperativo poder acogerlos, escucharlos y hacerlos construir con sus propias palabras el velo que cubrirá el vacío simbólico que el riesgo encarnara.

2. La orientación estructuralista, a su vez, problematiza el evento biológico de la pubertad, el enigma de lo sexual y lo real del cuerpo como decisivos para la noción psicoanalítica de adolescencia. Los trabajos de Stevens tal vez sean seminales para pensar tal noción y organizar un pensamiento sobre lo mismo. Según ese autor, apoyado en Lacan (2003a/1974), la adolescencia sería una respuesta a lo real de la pubertad que, como tal, se presenta al sujeto como un imposible de la estructura a nombrar y tener un saber estable sobre la diferencia 
de los sexos. "Frente al encuentro con lo imposible, el sujeto organiza una posibilidad para sí de una relación con el gozo; ese es su síntoma" (Stevens, 2004, p. 30).

Diversos autores del medio psicoanalítico como Guerra, Soares, Pinheiro y Lima (2012), por ejemplo, corroboran esa idea. Afirman que la adolescencia se configuraría en la enumeración de una serie de elecciones sintomáticas en relación con ese imposible. Con la llegada de la pubertad, ese punto de falla se representa, sea sobre la forma de cuerpo sexuado y púber, sea sobre la forma de encuentro con el otro: "Delante de esas imposibilidades que dan forma a la falta real de la pubertad, la adolescencia se presenta como forma sintomática de respuesta encontrada por el púber, en el intento por nombrar, enlazar ese punto de oscuridad" (p. 252, traducción nuestra).

El propio Stevens va a decir que el sujeto no se decidió totalmente en cuanto a sus elecciones de objeto al entrar en la adolescencia y tendrá que superarlas "aunque ellas ya sean colocadas; él tiene que decidir su elección por la supervivencia” (Stevens, 2004, p. 28, traducción nuestra). Esto significa que las elecciones del síntoma y de la organización de la fantasía establecidas en la infancia son reubicadas y puestas a prueba en la adolescencia. Más aún, para Melman (2000), la adolescencia sería el único momento de la vida en el cual una experiencia es susceptible de venir a modificar la fantasía que había sido instalada en la infancia.

De igual forma, pero tratando la adolescencia como "crisis", previamente Rassial (1997) afirma que la adolescencia es necesaria y estructuradora, a raíz del golpe con lo real ${ }^{3}$ constituido por la puber-

3 Como lo aclaran Pereira y Gurski (2014, nota 10), lo real es un concepto lacaniano que representa aquello que no puede ser simbolizado totalmente en la palabra o en la escritura o aquello que "no cesa de no escribirse". Es uno de los tres registros que, junto a lo simbólico y lo imaginario, fundan lo que Lacan denominó RSI -las instancias indisociables del nudo borromeano-. A grueso modo, lo real designa lo imposible de ser simbolizado, lo simbólico sería el lugar del significante y de la función paterna, y lo imaginario el lugar supremo de las identificaciones, de las ilusiones del Yo y de la alienación del sujeto. 
tad. Ese golpe envolvería no solamente la dimensión biológica sino también el desamparo del sujeto al ser lanzado al mundo, momento en el que las referencias simbólicas de la infancia son, en lo real, inoperantes. El agujero de lo real advenido con la pubertad constituiría un estado de desamparo: las referencias disponibles se muestran insuficientes, exigiendo del sujeto un significativo trabajo psíquico y el mantenimiento del compromiso con la herencia que le fue dada. El autor afirma que el gran drama que confunde en la adolescencia no sería tanto el de la ignorancia o el no saber sino que, al contrario, es el saber demasiado, que viene a ser como una mala repetición con retorno brutal luego de unos años inútiles de elaboración del olvido. Dicho saber en exceso agitaría el joven y perturbaría el medio a su alrededor. Entonces, el adolescente:

Se confronta y confronta a los otros con la impotencia, la interdicción y lo imposible: con la impotencia imaginaria que afecta un cuerpo construido como lo positivo de lo negativo, con la interdicción simbólica que constituyó el eje de la lengua que se prometía mentirosamente el goce, y con lo imposible real de un acto sexual que funda la relación al otro. (Rassial, 1997, p. 19, traducción nuestra).

Melman (2000, p. 21), al preguntar: ¿qué es un adolescente?, responde: es "un individuo que alcanzó la madurez y en el que esta madurez no es reconocida como tal". Para el autor, "lo real del sexo" o lo "real orgánico de los caracteres sexuales secundarios", adquiridos por los adolescentes, traduciría lo que llamó de "madurez", no admitida por la sociedad y cuya pulsión sexual habría de ser una vez más repetida. La confrontación del sujeto con lo real puberal remarcaría la imposibilidad del goce pleno de su condición corporal. Tal goce es rechazado por su entorno, y eso sin contar "con la Bejahung [afirmación] que permitirá al adolescente estar de acuerdo con su propio cuerpo" (p. 22). De eso resultaría, escribe Lima (2014), un despedazamiento de la imagen, una fractura del espejo, y lo simbólico mostrándose insuficiente para recubrir lo real. De ahí la importancia de la fantasía como ejercicio psíquico, apunta la autora. 
Hablando especialmente del acto infractor, esa perspectiva estructuralista nos permite hacer conjeturas en relación con cuanto tal acto puede surgir como respuesta al no saber qué hacer con el sexo, "al imposible del saber" (Souza, 2019, p. 65). El encuentro con lo real irreductible al lenguaje "se da en todos los momentos de la vida del sujeto, sin embargo, la pubertad aparece como un momento paradigmático" (Guerra et al., 2012, p. 171), sobre todo en casos en que la violencia se presenta como modo de vida o, como dicen Moreira et al. (2015, p. 294), un "modo de colocarse en la división de los dos sexos". Sobre eso Melman aclara que:

La violencia y la delincuencia son perfectamente normales en aquellos que no fueron reconocidos simbólicamente. La única manera que esas personas tienen para ser reconocidas es el pasaje al acto, ya que la palabra o el lenguaje se niegan a reconocerlas. [Así] el adolescente está expuesto a volverse delincuente y a poder ser violento. (Melman, 2000, p. 33, traducción nuestra).

Es muy común para un adolescente practicante de un acto antisocial percibirse al margen del derecho de participar de la realidad común de su entorno. Su relación con el saber es bastante alterada, una vez constatado que aquellos en los que confiaba en la infancia, en general los padres, se encuentran ahora incapaces de lidiar con su "crisis", de tratarla o de reconocer su condición sexual. Justamente por eso el sujeto puede quedar bastante vulnerable a los saberes considerados marginales. No es de extrañarse que, bajo dichas circunstancias, se encuentre más expuesto y vulnerable a la influencia de los que están fuera de la ley, de los tiranos, de los fundamentalistas o, dicho de otro modo, del perverso, como el psicoanálisis lo concibe. El perverso es aquel que se constituye y practica la perversión, o sea, la versión de la ley por sí mismo o a partir de sí mismo (versionem de per se o per versionem), rechazando la ley, transgrediéndola en beneficio de su goce, como también en beneficio de quien lo siga. Él, al contrario de la sociedad en general, se interesa por el adolescente, reconoce imaginariamente su pulsión sexual y ofrece condiciones reales para que sus modos de goce sean efectivos, mismo contra la ley. 
Luego, eso no se da sin costo: el perverso exige como moneda de cambio la sujeción incondicional. El adolescente puede hasta gozar con el aval del perverso, lo que muy frecuentemente ocurrirá, desde que sea servil y obediente a su tiranía, ya que el goce de todo perverso es hacer del otro -en este caso el adolescente- su objeto sexual, es decir, el objeto con el cual él goza y, al mismo tiempo, hace gozar. Como casos emblemáticos, basta mencionar algunos adolescentes que fueron sujetos de la investigación de Bolaños (2017), o muchos otros que son "soldados" del tráfico de drogas, que son miembros de pandillas de calle dirigidas por tiranos o que se someten a religiosos o a políticos fundamentalistas que a menudo lo hacen con disposiciones socialmente perversas.

De eso resulta un enredo: se vuelve difícil manejar clínicamente un adolescente que se encuentra pegado en esa estructura o modos perversos de goce, estando él en espacios de habla como los de investigación y extensión en el ámbito de las universidades (Bolaños, 2017; Boaventura Jr. y Pereira, 2015; Moreira et al., 2015; Guerra et al., 2012), bien como el del propio psicoanálisis convencional de consultorios. La fijación pulsional, en términos freudianos, es una máquina de goce de la cual nadie se quiere librar dado el quantum de satisfacción -incluso en el dolor- que dicha máquina da a todo individuo sujetado a ella (vendría de ahí el concepto de "sujeto" en psicoanálisis: sujetado a su propio inconsciente que es constituido por el deseo del Otro).

Mediante una sociedad que simbólicamente no reconoce al adolescente, que no le ofrece ideales societarios capaces de nombrar (o de renombrar) lo real púber que le asalta, ni el enigma de la sexualidad que esa misma sociedad insiste en hacerlo repetir, es de esperar que ese sujeto en transición agarre y se fije a las posibilidades de satisfacción pulsional que los perversos le conceden, aunque lo sujeten. La condición de margen en que se encuentra un perverso sirve como leitmotiv para la identificación del adolescente con él, ya que, como en un espejo, la marginalidad de ambos se refleja y se reconoce. La escucha del adolescente, bajo esas circunstancias, no puede desconocer dicha estructura de fijeza de goce bajo la pena de no conseguir disuadirlo de aquello que lo sujeta y, claro, lo esclaviza. 


\section{Los límites de las interpretaciones psicoanalíticas y lo que proponemos}

No cabe duda que tanto la orientación estructuralista como la culturalista son bastante fértiles para interpretar psicoanalíticamente la adolescencia contemporánea fuera del dominio del evolucionismo. Las dos sirven de norte para analizar las singularidades subjetivas de cada uno que se presentan a los que lidian cotidianamente con adolescentes al margen de la norma. Se vuelve urgente, por lo tanto, no aplazar y tomar a ese sujeto como

paradigma social de aquel que testimonia una herencia, tanto en términos personales como generacionales. Es necesario hacer un nuevo montaje, encontrar un lugar propio de enunciación. En ese sentido, nos parece que ellos padecen de transmisión de la falta como promotora de ellos en los diferentes tiempos. (Gurski, 2012, p. 160, traducción nuestra).

Un nuevo montaje nos parece fundamental una vez que ambas orientaciones muestran sus límites, aunque sean avances expresivos en relación a las teorías evolucionistas. Desde Ana Freud (1971), esas teorías se hicieron hegemónicas a lo largo del siglo xx para pensarse, no sin polémica, el psicoanálisis del niño y del adolescente. Las teorías evolucionistas, como las del desarrollo, esconden poco la matriz biologista en la que se basan, su sujeción a la orden médica y el reforzamiento de la distinción entre normal y patológico que, incluso ambiguamente admitida por el padre de Ana, Sigmund Freud, fue rechazada o cuestionada al avanzar sus estudios: "plausiblemente podemos suponer que llegamos aquí a la línea fronteriza -nunca bien nítidamente tratada- entre lo normal y lo patológico" (Freud, 1980c/1924, p. 222), pues "un Yo normal es, como norma general, una ficción ideal. En verdad, toda persona normal, es apenas normal en la media" (Freud, 1980d/1937, p. 268, traducciones nuestras).

Hablando de los posibles límites de las orientaciones culturalista y estructuralista, obviamente estamos considerando algo, a nuestro modo de ver, bien menos grave de aquello que representaron las teorías de desarrollo y su sumisión a los determinantes biológicos o biopo- 
líticos. A diferencia de ello, pero mostrando sus restricciones, podemos presumir que ambas tendencias impusieron a las singularidades subjetivas, y a sus formas múltiples de manifestación, algunas universales generalizadoras, que para la noción de adolescencia pueden significar una reducción de lectura o de clave de interpretación: de un lado, la pérdida de la eficacia simbólica de los ritos de pasaje, para los culturalistas; y de otro lado, la cristalización de lo real púber como disparadora de la adolescencia, para los estructuralistas. Veamos eso.

El mayor problema de la orientación culturalista al enfatizar el decline de los ritos de pasaje de las sociedades modernas y, como consecuencia, de su eficacia socializadora, está en la condición de elevarse a verdad -y de verdad universal, tal vez- la concepción teórica de un fenómeno en detrimento de las experiencias singulares y microfísicas. De ese modo, los culturalistas pueden quedar presos al forzar una interpretación unívoca de carácter fenomenológico para todas las prácticas y acontecimientos que pasan con nuestros adolescentes. Esa interpretación va a decir que serán ellos constituidos y se presentarán como tal en razón de no contar con límites sociales que les impusiesen una moral adulta, como supuestamente pasó en las sociedades tradicionales. Si eso guarda alguna verdad, no sería para todos los adolescentes de nuestro tiempo, tal vez solo para algunos.

Así, la lectura hegemónica de lo cultural de base fenomenológica puede eludir la polarización de las experiencias y prácticas cotidianas que se dan visibles o invisibles; glamurosas u ordinarias; rehén de la historia y de la cultura o rehén de una contingencia; como efecto de la biología humana o como efecto del pasaje al acto. La fenomenología no puede opacar la multiplicidad de la experiencia, ya que ninguna verdad fenoménica puede adjudicarse a sí misma las verdades plurales de la práctica. De ahí nuestra alerta, más que una advertencia.

De igual forma podemos alertar, si no interrogar, la univocidad interpretativa cuando los psicoanalistas de base estructuralista dicen que la adolescencia es una respuesta a lo real corporal de la pubertad. Considerar como verdad universal ese momento de transición en la vida de un sujeto, siendo él mismo un síntoma social de nuestra cultura en consecuencia del real puberal, no deja de ser una tesis bastante potente 
para pensar, desde el punto de vista lógico, las marcas que el enigma de la sexualidad imprime en los adolescentes de hoy. Pero, aunque "el Psicoanálisis (...) [tiene] indudablemente el mérito de desbiologizar la sexualidad e inscribir así la biología en un registro inminentemente simbólico" (Birman, 2006, p. 29, traducción nuestra), la tesis puede contribuir para fijarnos justamente en aquello que ella pretende combatir, o sea, nos puede relegar a una biología de los efectos o a una biología de lo real en la que la constitución adolescente dependería de los acontecimientos corporales que emergen en la pubertad.

Tomar esos elementos como disparadores, o igual como operadores lógicos para la asunción de la adolescencia como síntoma, nos puede, de nuevo, condicionar a una moral orgánica general de carácter biologista. Evidentemente, no sería un biologismo nivelado a las teorías del desarrollo, que no hacen otra cosa si no someter los operadores psíquicos a la moral orgánica, pero sería un constructo lógico que tiene en cuenta el concepto lacaniano de real como imposible de nombrar (Lacan, 2003b/1961-62; Bolaños y Pereira, 2019). Aun así, ese constructo quedaría condicionado a su irrupción en el cuerpo del púber.

Ahora, desde las décadas de los años 60 y 70 del siglo pasado, cuando las sociedades occidentales se juvenilizaron como efecto del protagonismo de los jóvenes en la época, y más aún después de fines de los años 80 cuando se virtualizaron los lazos sociales en un lenguaje demasiado adolescente, el enigma de la sexualidad viene borrando su estatuto de enigma. Eso no quiere decir que la sexualidad haya conseguido ser toda revelada, ya que no lo será. El encuentro con el otro sexo o con el sexo del otro jamás podrá ser vivido sin la dimensión de un desencuentro, esto es, de un no saber o de un supuesto saber en exceso. Fue lo que precisamente Freud descubrió en el inconsciente. Pero los usos del saber-poder que el adulto hace en relación con ese enigma de la sexualidad, manipulándolo, subyugando sus tutelados, exigiéndoles olvidos y represiones están con los días contados.

El saber está en el bolsillo, no es más el objeto del Otro. Antes, el saber era un objeto que era necesario buscar en el campo del Otro, era necesario extraerlo del Otro por las vías de la seducción, de la obediencia o de la exigencia. (Miller, 2015, s/p, traducción nuestra). 
Eso quiere decir que muy precozmente los sujetos aún infantiles, pero bastante adolescentizados, son capaces de saber mucho sobre el sexo lo que antes estaba interdicto, mismo sin que los caracteres secundarios surjan en sus cuerpos y sin que dependan de otro, de un adulto, que le sea responsable o detentor de ese supuesto saber.

La incidencia del mundo virtual, en el cual esos adolescentes viven más que aquellos que, como yo, ya somos de otra generación, hace con que el saber, antes depositado en los adultos, esos seres hablantes que eran los educadores, estando los padres incluidos en los educadores -era necesario el saber de ellos para acceder al saber-, esté ahora, automáticamente disponible mediante una posible demanda formulada a la máquina. (Miller, 2015, s/p, traducción nuestra).

Vivimos ahora en tiempos de "adolescencia generalizada" y de "adultez erosionada" (Pereira y Gurski, 2014), en los cuales un sujeto puede adolescer antes de la irrupción de la pubertad. Ya no es la excepción, es la regla. Y el mundo virtual de la web ayudó mucho a acelerar eso.

En la actualidad, un alargamiento de la adolescencia inicia hoy más temprano que anteriormente (...). Las clases sociales son arrancadas, hace mucho tiempo, de su condición infantil muy precozmente, oprimidas por el imperativo de sobrevivencia. (...). Para los niños de clase media y las élites, la adolescencia inicia más temprano y se extiende también por la edad adulta, de tal forma que se vuelve hoy más larga que décadas atrás. (Birman, 2006, p. 27, traducción nuestra).

No obstante, defendemos que la multiplicidad de la experiencia -y no la univocidad o biunivocidad- sea el operador lógico con el cual podamos interpretar psicoanalíticamente la adolescencia de nuestros tiempos. En razón a todos esos aspectos aquí problematizados, juzgamos bien el que se descienda hasta los detalles de la experiencia para saber hacer inventarios de las tantas formas de ser adolescente cuya vivencia de desinserción social volvió el timbre mayor de sus túneles precariamente escavados. No tendríamos sólo aquellos que sintonizarían su existencia en función del agujero en lo real causado por su 
cuerpo púber sexualizado, tampoco a aquellos que se encontrarían en una desviación societaria en función de no contar fenoménicamente con ritos tradicionales de pasaje que los impulsarían a la vida adulta. Tendríamos estos y muchos otros. Tendríamos múltiples salidas sintomáticas que, ciertamente, deberían de ser analizadas caso a caso, de acuerdo con sus vivencias singulares y microfísicas. A continuación presentamos algunas de las posibles maneras de interpretar la adolescencia y al adolescente actualmente, de acuerdo con nuestras investigaciones (Gurski y Pereira, 2019), terminando en la propuesta que hace Bolaños (2017):

Adolescentes a modo de Telémaco: la experiencia nos revela que hoy, al escuchar a los adolescentes en las investigaciones, en la extensión $\mathrm{y}$ en otros ambientes que reciben a aquellos considerados antisociales, en vulnerabilidad o en conflicto con la ley, se puede percibir cuánto los modos de vida y de síntoma se multiplican. Uno de esos modos puede ser teorizado como complejo de Telémaco ${ }^{4}$, esto es, como representante de aquellos adolescentes que se sienten a la deriva no tanto por la ausencia social de ritos de pasaje y sí por el debilitamiento de los significantes amos de una sociedad que actualmente vive los efectos del descenso de reguladores simbólicos patrilineales. Tales significantes representarían, como ya representaron en el pasado, ideales (ideales de Yo), diques o referentes que operarían para regular el goce de adolescentes -y de los sujetos en forma general- sirviéndoles a menudo de norte contra la condición de desorientación en la cual se encuentran habitualmente. Serían adolescentes que, al modo de Telémaco, se hacen nostálgicos del retorno del padre o del retorno de aquel que es vector de la ley con potencia para ordenarlos. En ese sentido, algunos jóvenes podrían sujetarse a los más diversos líderes, para bien o para mal, perversos o no, en la esperanza de encontrar en

4 Telémaco es hijo de Penélope y Ulises, cuyo padre dejó la familia para luchar en Troya cuando él era aún un bebé. Como narra la Odisea, de Homero, Telémaco pasa gran parte de su vida buscando indicios sobre el padre distante, acreditando que una vez vivo regresaría al hogar, aunque algunos quisiesen persuadirlo de tal aspiración. Recalcati (2014) va a elevar ese aspecto de la mitología griega a la condición de complejo psicoanalítico, así como Freud lo hiciera con Edipo, y en la perspectiva ética, como Lacan lo hiciera con Antígona. 
ellos algún significante de amo o algún rasgo paterno para identificarse en su ideal de Yo. La noción freudiana de Vatersehnsucht (la nostalgia del padre) tendría aquí su acepción máxima: "nos encontramos en una época de descenso irreversible del padre, pero igualmente en la época de Telémaco: las nuevas generaciones ven en dirección al mar esperando que algo del padre retorne" (Recalcati, 2014, p. 13, traducción nuestra).

1. Adolescentes ligados maternalmente: otro modo de algunos adolescentes presentarse repetidamente a nuestras intervenciones se refiere no a la línea paterna y sí a cierta indecisión del desligamiento materno como lo describen Boaventura Jr. y Pereira (2015). Sospechamos que sea un aplazamiento del descenso de las formas narcisistas de investiduras en objetos incestuosos de amor, de mantenerse fijos en el goce infantil y, con eso, en una cierta indiferencia sexual o en el propio rechazo para admitir tal diferencia. Llama la atención cuánto unos sujetos no esconden cómo son demasiado protegidos por sus madres, al mismo tiempo que, incondicionalmente, las defienden. Tienden a ser mimados por la permisividad y se mantienen en un juego dual de relaciones que se repite y que establecen con sus genitoras o con quienes las representan. Curiosamente algunos tienen los nombres de las madres o sus iniciales tatuadas en el propio cuerpo, aunque varias de ellas tengan biografías bastante complicadas de envolvimiento con la policía, con drogas e históricos de abandono. Pero, una vez indagados, los adolescentes las deifican y nos dicen comúnmente que "madre hay sólo una", que "es para siempre" o que "con la madre no se mete". Algunos que no tienen esos tatuajes, no dejan de manifestar el claro deseo de hacer lo mismo. Llegan a pelear entre sí por cualquier motivo que ofenda las imágenes de sus madres. Entonces, es posible inferir que el rechazo de esos adolescentes para tolerar la norma, para someterse a procesos educativos o a reglas institucionales podrían servirles como una forma de mantener inacabado algo de la relación materno filial, asegurando así la ilusión de ser, en la indiferencia sexual, un objeto de satisfacción de otro a la forma infantil. No tendríamos más propiamente el padre y sus substitutos interdictivos, pero la madre y su permisividad incestuosa. 
2. Adolescentes en exceso de goce: No hay como desconocer que de ese vacío dejado por el descenso de los ideales paternos un buen número de adolescentes va a invertir el orden de interdicción. Algunos jóvenes nos muestran que vivimos en sociedades no de la represión y sí del exceso. Se trata de una cultura del derecho al goce, de su maximización bajo la forma de satisfacción pulsional inmediata con la promoción, sin límites represivos, de ideales unidos al placer, a la alegría, al disfrute (Pereira, 2016). Cada adolescente es elevado, imperativamente, a la obligación de satisfacerse bajo la pena superegoica ${ }^{5}$ de verse diferente, o sea, de culparse por no conseguir gozar tanto como el orden social se lo exige. El dilema es que, cuanto más se accede al goce, más él se muestra inalcanzable y más ese adolescente se encuentra en deuda con el superyó. Si para la época de Freud (2010/1930), un sujeto debería producir cada vez más renuncia pulsional para responder al superyó, hoy él es empujado a producir cada vez más exceso de goce para igualmente responderle a esa instancia. Pero, un mundo más liberado genera, definitivamente, un mundo más angustiado debido al carácter insoportable del placer no regulado. No es de extrañar el motivo de la ansiedad ser invariablemente experimentada por muchos de esos adolescentes. Y eso es facilitado por las fragilidades actuales de los cuadros familiares, sociales e institucionales, por la disminución de la expectativa en relación a las autoridades, a las religiones y a las ideologías que, antes represivas, hoy se vuelven apaciguadoras de las funciones políticas de regulación pulsional. Como consecuencia habría una

Tendencia al desborde de goce generalizado, al pasaje al acto y a la sobredosis como formas de compulsión a la repetición (...). Tales excesos se nivelarían más a la pulsión de muerte que a la voluntad de potencia o a modos de afirmación y subjetivación del deseo. (Pereira, 2016, p. 109, traducción nuestra).

5 Relativo al superyó (o superego), que designa en psicoanálisis una de las tres instancias dinámicas que estructuran al sujeto humano y, al mismo tiempo lo divide, funcionando como una consciencia o autoridad moral internalizada en el inconsciente (Freud, 2011/1923). 
3. Adolescencia con vínculos parsimoniosos: de manera opuesta, salta a los ojos aquel grupo de adolescentes que demuestra un interés parsimonioso por las cosas, personas y excesos pulsionales, sin alterarse con cualquier estímulo externo más allá de lo necesario para resolverlo. Parece gastar libido sólo lo suficiente para mantenerse mínimamente conectado a la demanda del otro, pero sin dejarse esclavizar por ella o mismo suplantarla. Los intereses de esos jóvenes no muestran fuerza suficiente para mantenerse apasionados por una causa o por un acto, como normalmente se ha juzgado que es propio en ese momento de la vida. Nada los apasiona más que lo mínimo. De ahí el poder de conectarse o desconectarse rápidamente de una idea, una causa, un trabajo, de un interés sexual, de un acontecimiento, de un fervor religioso, de una alineación política etc., esto es sorprendente. Una cierta anestesia sintomática los embriaga al punto de que quien les escucha nunca sabe muy bien en donde residen sus deseos o incluso lo que los hace padecer o angustiar. Como en la clínica del deprimido, un adolescente bajo tal condición parece saber de antemano que no logrará responder a la demanda del Otro, desistiendo de hacerlo incluso antes de ponerse a prueba. La inhibición, en el sentido de eludir la angustia, demuestra ser una operación psíquica muy eficaz para garantizarle cierto apartamiento del ser. Sospechamos que una sociedad exageradamente horizontal, sin la verticalidad del vector del padre, puede estar generando, en algunos, una especie de fatiga casi corporal que ningún ideal los conmueve a punto de persuadirlos a no ceder de su deseo. Ellos, tal vez, no consigan convertir esa liberación de los amarres del padre en potencia creadora o en nuevo modo de vida cuya horizontalidad de las relaciones se descubre como posibilidad realmente fértil en la contemporaneidad. A su vez, encontramos en esos jóvenes algún índice de interés o alguna vivacidad por cierta causa, pero como semblantes que no se sustentan más que por un lapso de tiempo. Después se puede percibir ese interés de marchitarse y la consecuente evaporación de su vivacidad.

4. Adolescentes bajo la experiencia de soledad: algunos jóvenes pueden vivir aún los efectos de lo que Birman (2006) describiría como "un mundo que enfatiza excesivamente la rivalidad, pero que va- 
cía las relaciones de cambio más tiernas entre los niños" (p. 35). Para el autor, un sujeto en estas circunstancias tiene afectada su experiencia de alteridad con entornos bien particulares en razón de ese contraste, de modo que la soledad se vuelve una verdad crucial del universo actual vivido por el adolescente. Desde el punto de vista social, la disminución del número de hijos por familia, la crianza de los mismos en domicilios exclusivos con poca interacción, acentúa aún más el contraste, ya que coloca un obstáculo real para el mundo de intercambios entre los adolescentes. A su vez, el autor defiende que la soledad tiende a ser llenada con la presencia avasalladora de la televisión, de los juegos electrónicos, de los computadores, de los celulares, etc., de tal forma que esos sujetos conviven activamente con personajes virtuales con ideales imaginados, con historias alegóricas que pueden perturbar de sobremanera su ya precaria experiencia de alteridad. El cuerpo a cuerpo se desploma en pro de la virtualidad, dice Birman. Y deduce que la maquinaria electrónica contribuiría para que niños y adolescentes estén en contacto muy precozmente con temas y situaciones del mundo adulto, como la sexualidad, la violencia y las drogas. Esas experiencias pueden exponer a los sujetos a la casi ausencia de límites, de forma que la debilidad de los interdictos sobresalga como una problemática fundamental en la constitución psíquica. La mayor ausencia de los padres en el transcurrir del día, las prácticas de rivalidad en las escuelas, la poca interacción social donde habitan, entre otros factores, pueden dejar a los adolescentes sin un contrapunto seguro de frente a lo que sobre ellos mismos incide, imposibilitando la metabolización simbólica de dichas vivencias. Birman va a suponer que eso generó un impacto importante sobre niños y adolescentes de hoy, de forma que alteró las relaciones con sus propios cuerpos, con los interdictos y con el otro. A la manera de Lacan (2003b), el autor va a destacar cuanto no se puede subestimar el efecto de las imágenes sobre el funcionamiento biológico de cada uno en el espejo, "de forma que una cultura centrada en la imagen, como es la de nuestra actualidad, tendrá ciertamente efectos significativos sobre el organismo y la imagen corporal" (Birman, 2006, p. 36, traducción nuestra). 
5. Adolescentes vengadores: en el agravamiento de ese cuadro viene creciendo el número de adolescentes que, al modo de Columbine ${ }^{6}$, se identifican masivamente con personajes y acciones de objetos imaginarios que nuestras sociedades occidentales han producido ampliamente. Hay una especie de estilización de imágenes, como de juegos electrónicos, de cine de acción, de series televisivas -en general, llenos de escenas violentas y letales- de modo que llevan al joven a incorporar en su ideal del Yo rasgos imaginarios de un mundo virtualmente bélico y destructivo. Es como si el sujeto se transfiriera al interior de un juego y se percibiese, él mismo, como un "vengador solitario" que deberá actuar en razón de causas aparentemente difusas a los ojos del medio social alrededor. Impresiona cuánto la noción genuinamente norte-americana de "vengador solitario", que puebla el imaginario histórico de aquel país, en su marcha para el Oeste, y la construcción de súper héroes como seres ordinarios transformados en pura potencia, consiguen ejercer amplia influencia en el imaginario de otras naciones occidentales. Algo de esa estética se repite de manera capciosa: muchachos agredidos, violados, segregados y estigmatizados, con acceso anónimo e irrestricto a armas, al consumo y a la virtualidad sin barreras, con poco o ningún ideal, creencia, proyecto personal o sensación de pertenencia, se mimetizan en agentes de juegos y disparan sus supuestas venganzas contra su entorno sin compasión. Algunos llegan a exterminar al otro y a sí mismos en función de eso. Son los "cuadros de guerra" o las vidas no "susceptibles de luto" (Butler, 2015) que el vacío de nuestros horizontes puede estar produciendo en ciertos adolescentes. Tal vez ellos sean identificados como servidores del discurso de un señor -en el caso, los imperativos estilizados- volviéndose agentes de su

6 Referencia a la masacre escolar ocurrida el 20 de abril de 1999 en la Colombine High School, en el Estado norteamericano de Colorado, que resultó en un tiroteo perfectamente planeado por dos adolescentes, llevando a la muerte de 12 estudiantes y un profesor e hiriendo a otras 24 personas, para, luego, suicidarse. El evento fue el primero de una serie de otros, provocando numerosos debates acerca del control de armas, de la violencia social y en videojuegos, de los efectos del matoneo de pandillas (bullying), de psicopatologías juveniles, etc. En Brasil, los más emblemáticos fueron el de Realendo, RJ, en el 2011 y el de Suzano, SP, en el 2019. 
imaginada e imperiosa voluntad. De eso resultaría no algo de la herencia de la tragedia griega que nos funda como Occidente y sí del "narcisismo de causa triunfante" (Miller, 2015, s/p), contenida en esa nueva estética. No habría, aquí, una causa perdida ni una historia de castración, pero sí un servilismo desacomedido al significante amo que el señor perversamente engendra: una manera actual de regreso radical del Discurso del $\mathrm{amo}^{7}$ dejado por el vacío tanto por la sujeción al saber promovida por el discurso universitario cuanto por la objetivación de la vida promovida por el discurso del capitalista. Así como reflexiona Miller (2015) sobre los jóvenes occidentales que se someten al Estado islámico, podemos deducir que tales imperativos virtuales se volvieron el Uno de un discurso de la certeza del amo, sin agujero, sin dialéctica, cuya castración se presenta de nuevo reprimida. Suponemos que los adolescentes bajo tal condición se convierten en rehenes de ese Uno de la certeza mediante una sociedad supuestamente horizontal que no les puede tratar la fragilidad de sus cuerpos segregados y poco susceptibles de luto.

6. Adolescentes que se renombran: entre tantas otras maneras de interpretar múltiplemente los adolescentes de nuestros tiempos, llegamos a la experiencia de investigación psicoanalítica de Bolaños (2017), realizada con varios adolescentes latinoamericanos urbanos en condiciones antisociales, practicantes del Hip Hop (raperos y grafiteros) y también poco susceptibles de luto. Curiosamente, en los espacios de habla propiciados por Bolaños en su experiencia de investigación, los adolescentes se presentaron ante él como jóvenes que, al deambular por las calles, usan diferentes estrategias de socialización y reconocimiento, entre ellas el cambio de sus nombres, bautizándose con apodos o formas diversas de renombramiento tales como un número, un neologismo, un

7 El discurso del Amo es, originalmente, uno de los cuatro discursos introducidos por Lacan en forma de algoritmo para explicar el lazo social o las formas en que las personas se relacionan, junto con los discursos de la Universidad, de la Histeria y del Analista. Lacan todavía formaliza un quinto discurso, derivado del algoritmo del Amo, llamado discurso del Capitalista que, a diferencia de los otros, no promueve el lazo social, pero cosifica el sujeto o lo nivela a la condición de objeto de consumo. Sobre este tema, ver Pereira, 2016. 
nombre de santo, una firma del grafiti, entre otros. Son estrategias que desdicen bastante de lo que se piensa que ellos son: rumberos, soñadores, consumidores, entre muchos otros imaginarios que la condición adolescente despierta en adultos profesionales, gobernantes, medios de comunicación, etc. Ahora, si el nombre propio para el psicoanálisis fija a un cuerpo un significante amo atribuido por el Otro, haciendo a ese cuerpo identificarse y alienarse a tal significante (Lacan 2003b/1961-1962), más que un modismo, el rebautizo parece extraer, supuestamente, a esos adolescentes de sus contextos familiares para otros de sus ideales, para donde comenzarían de "cero" o simplemente, para donde no tienen alguien o algo igual a ellos. De ahí tenemos el apelativo de par-cero que Bolaños tomó en la investigación. Bolaños (2017) y después Bolaños y Pereira (2019) revelan las diversas vicisitudes de un mismo acto que es el de rebautizarse. Una adolescente, por ejemplo, crea un nombre santo para ella que justificaría su unión mística con la madre; otro adolescente se renombra con un número cabalístico en función del lugar que él ocupa entre sus hermanas, padres y compañeros; otro, aún más, se rebautiza con un nombre que quiere connotar provocación lenguajera, cinismo y humor, para, con él, ser reconocido. Entre tanto Bolaños va a concluir que, aparentemente en donde habría un des-enraizamiento del adolescente en relación a sus orígenes, surge un inter-juego o un juego duplo de separación y de nueva alienación, fomentada por narcicismos y voluntad de pertenencia. No se encontró en ese renombramiento ninguna gran convulsión, idealismos o acto de ruptura con las tradiciones. Al contrario, deducimos con Bolaños que un impulso cristiano -el acto del bautismo- permanece siendo la movilidad de algunos de esos jóvenes latinos cuyos horizontes no les parecen muy largos y cuyos vacíos de sus búsquedas y desinserciones chocan con lo social instituido que no les parece ofrecer algo muy diferente de ese mismo vacío.

Es obvio que las múltiples formas de interpretar psicoanalíticamente a un adolescente en condiciones adversas, antisociales, delincuenciales o en riesgo no se agotan con esos modos sintomáticos de adolescencia que describimos arriba. De igual forma, esos modos no sirven de cartilla para identificar formas diferentes de hoy ser joven 
en conflicto con la norma y la sociedad. Tampoco se deben extrañar aquellos que en sus interpretaciones mezclan dos o más formas, además de otras no descritas aquí. Nuestra intención fue dilatar las perspectivas de análisis y de descripciones para que también otros puedan hacerlo. Eso sin desconocer que muchas otras fuentes traen los más diversos testimonios sobre el trabajo social de psicoanalistas, como ha hecho Bolaños (2017), que crean espacios de habla y de escucha en el ámbito de la atención a adolescentes en condiciones de segregación y de adversidad social.

\section{Conclusión: ¿qué quiere un adolescente?}

Estos modos sintomáticos de adolescencia que desarrollamos aquí nos hacen preguntar de pronto ¿qué buscaría un adolescente estando él en tan múltiples condiciones?, ¿qué desearía él encontrar? $\mathrm{O}$, parafraseando a Freud, ¿qué quiere al final un adolescente?

En la línea del inventor del psicoanálisis, Winnicott (1975, p. 195) reconoce que "en la fantasía inconsciente crecer es inherentemente un acto agresivo" y que es propio de la constitución adolescente forjar simbólicamente la "muerte de alguien". Eso, de por sí, ya aludiría a un modo de inscripción de su deseo - ¿qué quiere?-. Esa muerte tiene que ver con la hipótesis freudiana del "desligamiento del padre" y también de todos aquellos que le sucederán, sean maestros, profesores, tutores, reeducadores, técnicos sociales, esto es, aquellos que institucionalmente regulen sus impulsos; así, serán ellos ambiguamente amados y rechazados; deseados y despreciados; idealizados y olvidados.

[El adolescente] Comprueba que el padre ya no es el más poderoso, el más sabio y el más acaudalado de los seres; comienza a dejar de estar conforme con él; aprende a criticarle y a situarle en la escala social, y suele hacerle pagar muy cara la decepción que le produjera. Todas las esperanzas que ofrece la nueva generación pero también todo lo condenable que presenta- se originan en este apartamiento del padre. En esta fase evolutiva del joven hombre acaece su encuentro con los profesores. Comprenderemos ahora la 
actitud que adoptamos ante nuestros profesores del colegio. Estos hombres, que ni siquiera eran todos padres de familia, se convirtieron para nosotros en sustitutos del padre. También es ésta la causa de que, por más jóvenes que fuesen, nos parecieran tan maduros, tan remotamente adultos. Nosotros les transferíamos el respeto y la veneración ante el omnisapiente padre de nuestros años infantiles (Freud, 1980b/1914, p. 288, traducción nuestra).

Sabemos que esos sustitutos no pueden ayudar mucho a los adolescentes, a no ser que sobrevivan ilesos, sin alterarse y sin el abandono de cualquier principio. Ellos, los sustitutos, deben mantener la responsabilidad de acompañarlos, sin dejarlos jamás a la deriva o abandonarlos (Winnicott, 1975; 2005). La adolescencia hereda las características y exigencias sociales del tiempo en la cual está inscrita. En el caso de nuestra contemporaneidad, los modos de delinquir, como también los problemas escolares, fracasos, rechazos, confrontaciones, vienen generando formas muy peculiares de insurrección de jóvenes que no pueden dejar de componer el campo de acción de psicoanalistas atentos a las subjetividades de su tiempo y de su lugar. Un adolescente en esas condiciones adversas habría de querer, entonces, a un psicoanalista ya que:

[...] lo que es más benéfico para un adolescente en dificultades, es encontrar, al mismo tiempo, un psicoanalista -quiero decir, la persona-, encontrar el adulto en quien puede confiar [...], sin discurso parental, ni de educador, pero manteniendo con él ese lugar específico que es el nuestro. (Melman, 2000, p. 26-27, traducción nuestra).

Es decir, como en un encuentro con un psicoanalista, tal vez el adolescente busque un adulto que le sirva como un otro referente, que le despierte la confianza, que no segregue, que no haga grandes discursos, ni sea moralista. Él desea quizás alguien que lo escuche, que reconozca y sepa acoger al sujeto en sus condiciones adversas o en sus múltiples síntomas, ayudándolo a elaborarse. Para eso es fundamental que se tenga una intervención lo más posible inesperada, permitiendo al sujeto tener una invención singular contra la cara mortífera del síntoma. En otras palabras: que se consiga civilizar un poco el impulso de muerte de cada joven en la difícil y necesaria conquista de su lugar social. 


\section{Agradecimientos}

Al CNPq y a la Fapemig, órganos brasileños de financiación pública, por fomentar las investigaciones que fundamentan el presente artículo. Y a Diego Bolaños por la traducción de la versión original.

\section{Referencias bibliográficas}

Birman, J. (2006). Tatuando o desamparo: a juventude na atualidade. Em Cardoso, M. R. (org.). Adolescentes. São Paulo, Brasil: Escuta.

Boaventura Jr., M. e Pereira, M. R. (2015). "Lá fora... na rua é diferente!". Adolescência, escola e recusa. Curitiba, Brasil: Appris.

Bolaños, D. (2017). Constitución de subjetividad en adolescentes integrantes de agrupaciones juveniles de ciudad en Mar del Plata (Argentina) y Cali (Colombia). Belo Horizonte: FaE-UFMG (tese de doutorado do Programa de Doutorado LatinoAmericano em Educação).

Bolaños, D. y Pereira, M.R. (2019). Re-nacimientos y bautismos en el rap: misticismo y religiosidad representados en seudónimos de adolescentes. Affectio Societatis, 16(30), 39-62. Recuperado de: https://aprendeenlinea. udea.edu.co/revistas/index.php/affectiosocietatis/issue/view/3297.

Butler, J. (2015). Quadros de Guerra: quando a vida é passivel de luto? Rio de Janeiro, Brasil: Civilização Brasileira.

Freud, A. (1971). Infância normal e patológica. Determinantes de desenvolvimento. Rio de Janeiro, Brasil: Zahar.

Freud, S. (1980a/1905). Três Ensaios sobre a teoria da sexualidade. Em Edição Standard Brasileira das Obras Psicológicas Completas de Sigmund Freud (vol. 7, pp. 129-256). Rio de Janeiro, Brasil: Imago.

Freud, S. (1980b/1914). Algumas reflexões sobre a psicologia do escolar. Em Edição Standard Brasileira das Obras Psicológicas Completas de Sigmund Freud (vol. 13, pp. 285-290). Rio de Janeiro, Brasil: Imago.

Freud, S. (1980c/1924). Dissolução do complexo de Édipo. Em Edição Standard Brasileira das Obras Psicológicas Completas de Sigmund Freud (vol. 19, pp. 217-228). Rio de Janeiro, Brasil: Imago.

Freud, S. (1980d/1937). Análise terminável e interminável. Em Edição Standard Brasileira das Obras Psicológicas Completas de Sigmund Freud (vol. 23, pp. 247-290). Rio de Janeiro, Brasil: Imago.

Freud, S. (2010/1930). O mal-estar na civilização. En: Freud, S. Obras completas (vol. 18, pp. 13-123). São Paulo, Brasil: Companhia das Letras. 
Freud, S. (2011/1923). O Eu e o Id. Em Obras Completas (vol. 16, pp. 13-74). São Paulo, Brasil: Companhia das Letras.

Guerra, A., Soares, C., Pinheiro, M. y Lima, N. (2012). Violência urbana, criminalidade e tráfico de drogas: uma discussão psicanalítica acerca da adolescência. Psicologia em Revista, 18(2), 247-263.

Gurski, R. (2012). Três ensaios sobre juventude e violência. São Paulo, Brasil: Escuta.

Gurski, R. y Pereira, M. R. (2016). A experiência e o tempo na passagem da adolescência contemporânea. Psicologia USP, 27(3), 429-440.

Gurski, R. y Pereira, M. R. (2019). Quando a psicanálise escuta a socioeducação. Belo Horizonte, Brasil: Fino Traço.

Lacadée, P. (2011). O despertar e o exílio. Ensinamentos psicanalíticos da mais delicada das transições: a adolescência. Rio de Janeiro, Brasil: Contracapa.

Lacan, J. (2003a/1974). Prefácio a "O despertar da primavera". Em Outros Escritos. Rio de Janeiro, Brasil: Zahar.

Lacan, J. (2003b/1961-1962). A identificação: seminário. Recife, Brasil: Centro de Estudos Freudianos.

Lima, N. L. (2014). A escrita virtual na adolescência: uma leitura psicanalítica. Belo Horizonte, Brasil: UFMG.

Melman, C. (2000). O que é um adolescente? Em O Adolescente e a modernidade. Congresso Internacional de Psicanálise e suas conexões. Tomo II. Rio de Janeiro, Brasil: Companhia de Freud.

Miller, J-A. (2015). Em direção à adolescência. Intervenção de encerramento da 3a Jornada do Instituto da Criança, Paris, França: 10 jun.

Moreira, J., Guerra, A., Oliveira, N., Souza, J., Soares, C. (2015). Medidas socioeducativas com seus dispositivos disciplinares: o que, de fato, está em jogo nesse sistema? Psicologia Política, 15(3), 285-302.

Paladino, E. (2005). O adolescente e o conflito de gerações na sociedade contemporânea. São Paulo, Brasil: Casa do Psicólogo.

Pereira, M. R. y Gurski, R. (2014). A adolescência generalizada como efeito do discurso do capitalista e da adultez erodida. Psicologia \& Sociedade, 26(2), 376-383.

Pereira, M. R. (2016). O nome atual do mal-estar docente. Belo Horizonte, Brasil: Fino Traço/Fapemig.

Pereira, M. R. (2019). Que acolhimento desejamos aos nossos adolescentes e jovens? Em Minas Gerais. Conversas com a socioeducação: pensando a acolhida no atendimento socioeducativo. Belo Horizonte, Brasil: CEAF/TJMG.

Ponnou, S. (2016). Le travail social à l'épreuve de la clinique psychanalytique. Paris, França: L'Harmattan.

Rassial, J. (1997). A passagem adolescente. Porto Alegre, Brasil: Artes e Ofícios. 
Recalcati, M. (2014). Il complesso de Telemaco. Genitori e figli dopo il tramonto del padre. Milão, Itália: Feltrineli.

Ruffino, R. (2000). Adolescência e modernidade. Em O Adolescente e a modernidade. Congresso Internacional de Psicanálise e suas conexões. Tomo II. Rio de Janeiro, Brasil: Escola Lacaniana de Psicanálise.

Souza, J. (2017). A elite do atraso. Rio de Janeiro, Brasil: Leya.

Souza, M. (2019). O lugar da verdade do sujeito em uma instituição socioeducativa. Belo Horizonte, Brasil: Fafich-UFMG (dissertação de Mestrado em Psicologia).

Stevens, A. (2004). Adolescência, sintoma da puberdade. Clínica do contemporâneo. Curinga, 20, 27-39.

Tubert, S. (1999). A morte e o imaginário na adolescência. Rio de Janeiro, Brasil: Companhia de Freud.

Winnicott, D. (1975). O brincar e a realidade. Rio de janeiro, Brasil: Zahar.

Winnicott, D. (2005). Privação e delinquência. São Paulo, Brasil: Martins Fontes. 